\title{
The Primary Care Physician and the Unsafe Older Drivers
}

\author{
Malaz Boustani, MD,MPH $1,2,3$ \\ ${ }^{1}$ Indiana University Center for Aging Research, Indianapolis, IN, USA; ${ }^{2}$ Regenstrief Institute, Inc., 1050 Wishard Blvd., RG6, Indianapolis, IN 46202- \\ 2872, USA; ${ }^{3}$ Indiana University Department of Medicine, Indianapolis, IN, USA.
}

DOI: $10.1007 / \mathrm{s} 11606-007-0132-5$

() 2007 Society of General Internal Medicine 2007;22:556-557

$\mathrm{O}$ lder adults receiving care from a primary care physician have complex biopsychosocial needs. It is estimated that $50 \%$ of these patients suffer from at least three chronic conditions, $15 \%$ have cognitive impairment, $65 \%$ report musculoskeletal pain, $31 \%$ feel anxious, and $21 \%$ are hospitalized annually. ${ }^{1,2}$ The primary care health system is the main site of health care delivery for these older adults. However, this health care system is facing a major challenge of delivering safe, highquality, and cost-effective services to its patients in general and to those with complex biopsychosocial needs in particular. ${ }^{3-6}$ The physicians in a primary health care system have insufficient time to spend with their patients and feel overworked and dissatisfied. ${ }^{4}$ Any suggested add-on assessment, intervention, or change to this system must take into account this reality.

In this issue of our journal, Dr. Jang and his colleagues ${ }^{7}$ provide very useful information related to the physician's role in decreasing the societal burden of unsafe older drivers. The investigators surveyed 460 English-speaking Canadian family physicians and collected data on the physicians' attitudes and practice's patterns related to assessing the driving fitness of patients aged 65 years and older. The methodological quality of this survey had no fatal flaw. Surveying primary care physicians is a challenge and thus, the ability of the investigators to accomplish a response rate of $67 \%$ is impressive. The responders' characteristics did not differ for those of the physicians who were originally targeted for the survey. Furthermore, the authors presented their survey findings in accordance with the guidelines of the American Association for Public Opinion Research. The survey found that the majority of primary care physicians are not confident in their ability to assess the driving fitness of their older patients and that they do not consider themselves the most qualified professionals to perform such an assessment. Moreover, the physicians felt that reporting unsafe drivers negatively affects their relationships with their patients and that revoking patient's driving license is not a benign intervention and may lead to negative consequences for both the patient and the family. ${ }^{7}$ Despite these attitudes and the perceived needed resources of time and education to perform the driving fitness assessment, $88 \%$ of the primary care physicians held themselves legally responsible for reporting unsafe drivers. The paradox of taking the responsibility of an action without having the needed skills

Published online February 6, 2007 and the resources to execute such an action may be unique to the primary care physicians and their mission of addressing the various medical needs of their patients.

Another interesting finding from this survey is the fact that the presence of a legally mandated policy may lead to higher reporting of unsafe drivers, but this might simultaneously be a disincentive to perform a driving fitness assessment, thus leading to lower rates of identification of unsafe drivers. Using the findings of their survey, the authors concluded that reducing the burden of unsafe drivers demands the development of further educational interventions that could improve the primary care physician's skills in conducting driving fitness assessments and counseling unsafe drivers to stop driving. However, such an intervention might be ineffective for several reasons. First, there are educational materials currently available, via the Canadian and the American Medical Associations' handbooks, on driving assessment and related issues, ${ }^{8,9}$ but few physicians are using them. ${ }^{7}$ Second, the interaction time between the older patient and the primary care physician is saturated with issues related to preventive services, self-management, chronic and acute care management, and counseling. Is there time to perform such an assessment and, among patients who fail, to intervene? Third, the financial cost of conducting a driving fitness assessment may be considered exorbitant by the payer. There is no clear financial incentive for Medicare or other insurance payers to cover the cost of a driving fitness assessment conducted by an expensive provider, such as a physician, when the same service could be provided by less-expensive professionals such as occupational therapists or even the Department of Motor Vehicles.

The idea of shifting the responsibilities of reporting and identifying unsafe drivers to the medical profession may not be a good public health policy. When evaluating the societal and health care burden related to unsafe older drivers and considering reallocating public resources, the primary care physician and the health care policy makers should take into consideration the other medical conditions that affect older adults and the driving safety profile of other age groups such as those aged 25 to 34 years.

In 2005, there were approximately 35 million Americans aged 65 years and older constituting $12 \%$ of the entire United States population. ${ }^{10}$ It is estimated that 6,500 individuals from this cohort died in the same year from motor vehicle crashes, 633,000 died from heart disease, 400,000 deceased due to cancer, and 145,000 died from cerebrovascular disease. ${ }^{11,12}$ Thus, from the public health perspective allocating resources to save the lives of the 6,500 older individuals who died from motor vehicle crashes may not seem to be a wise decision except if the public resources are unlimited and the cost of such life-saving process is very low. 
Table 1. Contrasting Individuals Aged 25 to 34 Years with Those Aged $\geq 65$ Years $^{9}$

\begin{tabular}{llc}
\hline \hline & $\begin{array}{l}\text { Age 25-34 } \\
\text { years }\end{array}$ & $\begin{array}{c}\text { Age } \geq 65 \\
\text { years }\end{array}$ \\
\hline US population (\%) & 14 & 12 \\
Overall MVF (\%) & 16 & 15 \\
Annual MVF rate per 100,000 population & 18 & 18 \\
MVF due to alcohol use in this age group & 32 & 7 \\
(\%) & 31 & 62 \\
MVF while using seatbelt in this age & & 60 \\
$\quad$ group (\%) & 71 & \\
MVF with the victim being the driver in & & \\
this age group (\%) &
\end{tabular}

MVF: motor vehicle crashes-related fatality

In 2005 , there were 43,443 motor vehicle fatalities in the United States. ${ }^{11}$ The majority, $76 \%$, of these fatalities took place among the motor vehicle occupants, not the passengers; $50 \%$ occurred during the daylight; 55\% happened in rural areas, which lack public transportation; 59\% took place among those who failed to use their seatbelt; 39\% were related to alcohol use; and $45 \%$ involved drivers with previously recorded crashes, license suspensions, or speeding convictions. ${ }^{11}$ In contrasting the 2005 traffic safety facts among the two age groups, those aged $\geq 65$ years and those aged 25 to 34 years, it appears that both groups have similar fatality rates from motor vehicle crashes per 100,000 population, but the motor vehicle fatalities due to alcohol or not using seatbelts, both possibly preventable conditions, were actually higher among the younger drivers (see Table 1). ${ }^{11}$ However, after adjusting for the annual vehicle mile driven, the motor vehicle fatality rates were higher among the older drivers. In fact, based on estimated annual travel, the fatality rate for drivers aged 85 years and older is nine times higher than the rate for drivers aged 25 to 69 years. ${ }^{13}$

Reviewing the above data suggests two strategies to save American lives. First, concentrate resources, energy, and skills on combating heart disease, stroke, and cancer among older adults, and ensuring the health care system, including primary care providers, is performing well to accomplish such goals. Thus, a primary care provider with a mission of improving the mortality profile of all Americans may have a hard time justifying the time and resources required to obtain the requisite skills and to routinely assess the driving fitness of his or her older patients. Second, channel resources to the police forces and the Departments of Motor Vehicles so they can decrease those driving under the influence of alcohol or drugs, can emphasize seatbelt use, and can monitor driving records.

In conclusion, enhancing and supporting the capability of the primary health care system, not only the physicians, to work with the other community systems such as the Department of Motor Vehicles, the Police Force, the Department of Health, and other governmental agencies may be the only costeffective solution to the challenge of decreasing the burden of unsafe drivers. Such enhancement could be accomplished via several system-based delivery innovations such as the implementation of the Chronic Care Model. ${ }^{14}$ This model offers a flexible and comprehensive framework to redesign health systems in accordance with local resources and demands. It recognizes that communities will vary greatly in the available resources and that these resources will change over time. Moreover, the model emphasizes the importance of collaboration and coordination of care across different health care providers, family, and community organizations and agencies. Focusing on retraining overworked, dissatisfied, and underappreciated primary care physicians to assess driving fitness in older adults may negatively impact the entire health care system via resource shifting and redistribution.

Acknowledgment: Dr. Boustani is supported by the Paul B. Beeson K23 Career Development Award \# 1-K23-AG026770-01.

Corresponding Author: Malaz Boustani, MD, MPH; Regenstrief Institute, Inc., 1050 Wishard Blvd., RG6, Indianapolis, IN 462022872, USA (e-mail: mboustani@regenstrief.org).

\section{REFERENCES}

1. Sha MC, Callahan CM, Counsell SR, Westmoreland GR, Stump TE, Kroenke K. Physical symptoms as a predictor of health care use and mortality among older adults. Am J Med. 2005;118(3):301-6.

2. Boyd CM, Darer J, Boult C, Fried LP, Boult L, Wu AW. Clinical practice guidelines and quality of care for older patients with multiple comorbid diseases: implications for pay for performance. JAMA. 2005;294(6):71624

3. Callahan CM, Boustani MA, Unverzagt FW, et al. Effectiveness of collaborative care for older adults with Alzheimer disease in primary care: a randomized controlled trial. JAMA. 2006;295(18):2148-57.

4. Bodenheimer T. Primary care in the United States. Innovations in primary care in the United States. Br Med J. 2003;326(7393):796-9.

5. Counsell SR, Callahan CM, Buttar AB, Clark DO, Frank KI. Geriatric Resources for Assessment and Care of Elders (GRACE): a new model of primary care for low-income seniors. J Am Geriatr Soc. 2006;54(7):1136-41.

6. Tanner CE, Eckstrom E, Desai SS, Joseph CL, Ririe MR, Bowen JL. Uncovering frustrations. A qualitative needs assessment of academic general internists as geriatric care providers and teachers. J Gen Intern Med. 2006;21(1):51-5.

7. Jang RW, Man-Son-Hing M, Molnar FJ, et al. Family physicians' attitudes and practices regarding assessments of medical fitness to drive in older persons. J Gen Intern Med. 2007; (DOI 10.1007/s11606-0060043-x).

8. Canadian Medical Association. Determining medical fitness to drive: a guide for physicians. 6th ed. Ottawa, Ontario: Canadian Medical Association, 2000. Available from: http://www.cma.ca/index.cfm/ ci_id/18174/la_id/1.htm. Accessed January 3, 2007.

9. Wang CC, Kosinski CJ, Schwartzberg JG, Shanklin AV. Physician's Guide to Assessing and Counseling Older Drivers. Washington, DC: National Highway Traffic Safety Administration; 2003. Available at: http://www.nhtsa.dot.gov. Accessed January 3, 2007.

10. U.S. Census Bureau, Population Division. Annual Estimates of the Population by Sex and Five-Year Age Groups for the United States: April 1, 2000 to July 1, 2005 (NC-EST2005-01). Available at: http://www.census. gov/popest/national/asrh/NC-EST2005-sa.html. Accessed January 3, 2007

11. U.S. Department of Transportation. Traffic Safety Facts 2005. A Compilation of Motor Vehicle Crash Data from the Fatality Analysis Reporting System and the General Estimates System. Available at: www. dot.gov. Accessed January 3, 2007.

12. Desai MM, Zhang $\mathbf{P}$, Hennessay $\mathbf{C H}$. Surveillance for Morbidity and Mortality among Older Adults-United States, 1995-1996. Surveillance summaries. December 17, 1999;48(SS08):7-25. Available at: www.cdc. gov/mmwr/preview/mmwrhtml/ss4808a2.htm. Accessed November 27, 2006

13. Wang CC, Carr DB; Older Drivers Project. Older driver safety: a report from the older driver's project. J Am Geriatr Soc. 2004;52(1):143-9.

14. Bodenheimer T, Wagner EH, Grumbach $\mathbf{K}$. Improving primary care for patients with chronic illness. JAMA 2002;288:1775-9. 